\title{
Increase of the critical current density of MgB2 superconducting bulk samples by means of methylene blue dye additions
}

\section{Grivel, Jean-Claude; Rubešová, K.}

Published in:

Physica C: Superconductivity and its Applications

Link to article, DOI:

10.1016/j.physc.2019.1353506

Publication date:

2019

Document Version

Peer reviewed version

Link back to DTU Orbit

Citation (APA):

Grivel, J-C., \& Rubešová, K. (2019). Increase of the critical current density of MgB2 superconducting bulk samples by means of methylene blue dye additions. Physica C: Superconductivity and its Applications, 565, [1353506]. https://doi.org/10.1016/j.physc.2019.1353506

\section{General rights}

Copyright and moral rights for the publications made accessible in the public portal are retained by the authors and/or other copyright owners and it is a condition of accessing publications that users recognise and abide by the legal requirements associated with these rights.

- Users may download and print one copy of any publication from the public portal for the purpose of private study or research.

- You may not further distribute the material or use it for any profit-making activity or commercial gain

- You may freely distribute the URL identifying the publication in the public portal 
See discussions, stats, and author profiles for this publication at: https://www.researchgate.net/publication/334543692

Increase of the critical current density of MgB2 superconducting bulk samples by means of methylene blue dye additions

Article in Physica C Superconductivity · July 2019

DOI: 10.1016/j.physc.2019.1353506

\section{CITATION}

1

2 authors:

Jean-Claude Grivel

Technical University of Denmark

243 PUBLICATIONS 2,442 CITATIONS

SEE PROFILE
READS

39

Katerina Rubesova

University of Chemistry and Technology, Prague

47 PUBLICATIONS 193 CITATIONS

SEE PROFILE

Some of the authors of this publication are also working on these related projects:

Project Ternary oxide phase equilibria View project

Project Thermal decomposition studies of metallorganic compounds View project 


\title{
Increase of the critical current density of $\mathrm{MgB}_{2}$ superconducting bulk samples by means of methylene blue dye additions
}

\author{
J.-C. Grivel1* and K. Rubešová ${ }^{2}$ \\ ${ }^{1}$ Department of Energy Conversion and Storage, Technical University of Denmark, DK-4000 \\ Roskilde, Denmark \\ ${ }^{2}$ University of Chemistry and Technology, Department of Inorganic Chemistry, Technická 5, \\ Prague 6, 166 28, Czech Republic
}

\section{Abstract}

$\mathrm{MgB}_{2}$ bulk samples were made by means of reaction of elemental $\mathrm{Mg}$ and $\mathrm{B}$ powders with or without additions of methylene blue trihydrate, a carbon source, which melts at high temperature upon decomposition. The $T_{c}$ of the $\mathrm{MgB}_{2}$ phase as well as its a-axis parameter were decreased as a result of carbon doping, whereas the c-axis parameter only shows a weak tendency for increasing. The critical current density of $\mathrm{MgB}_{2}$ was improved both in self field and under applied magnetic field for $T \leq 25 \mathrm{~K}$, the best results being obtained for $0.5-1.0 \mathrm{wt} . \%$ methylene blue trihydrate addition. Based on normalized flux pinning force $(f(b))$ versus reduced field $(b)$ plots, it was found that the flux pinning mechanism at low reduced field is similar for all samples, with a behavior close to the predictions of the point pinning model. However, for $b$ larger than 1 , the behavior of $f(b)$ is significantly altered in the methylene blue trihydrate added samples and tends towards the surface pinning model. Methylene blue trihydrate is an efficient carbon source and furthermore provides a liquid phase between $200^{\circ} \mathrm{C}$ and $450^{\circ} \mathrm{C}$, which may have some influence on the critical current density improvements at low field.

Keywords: $\mathrm{MgB}_{2}$; doping; carbon; methylene blue; dye

\section{*Corresponding author}

Email: jean@dtu.dk 


\section{Introduction}

Magnesium diboride $\left(\mathrm{MgB}_{2}\right)$, being made of abundant and non-toxic constituent elements, and thanks to its transition temperature $\left(T_{c}\right)$ close to $40 \mathrm{~K}$, is among the most promising superconducting materials for large scale applications. In the form of wires or bulk samples, it has already been used for demonstration units, including high field magnets [1,2], energy storage devices $[3,4]$, high power cables [5], racetrack coils [6], etc. In spite of these successful realizations, further improvements of the critical current density $\left(j_{c}\right)$ performance of $\mathrm{MgB}_{2}$ wires and bulk samples under the application of magnetic fields are desirable since $j_{c}$ tends to be severely suppressed when a magnetic field is acting on the material. This is especially important if $\mathrm{MgB}_{2}$ is meant to be used at an operation temperature of $20 \mathrm{~K}$. One strategy for this purpose consists in the addition of nanoparticles acting as flux pinning centers [7-11]. Carbon doping on the boron sites in the $\mathrm{MgB}_{2}$ crystal lattice is also known to be effective in enhancing the pinning force and hence the $j_{c}$ of $\mathrm{MgB}_{2}$ under high magnetic fields [1220]. This is in contrast to the general tendency resulting from foreign element doping on the $\mathrm{Mg}$ sites [21-26], as well as of Al doping on the B sites [27-31], which induce adverse effects or only limited improvements of the $j_{c}(B)$ performance due to the influence of these elements on various parameters. Nevertheless, even carbon doping often results in a lowering of the $j_{c}$ values under self-field and moderate applied magnetic field conditions [14-16,32,33]. Improving the $j_{c}$ performance of $\mathrm{MgB}_{2}$ samples at high magnetic fields without compromising their properties at lower fields is therefore still an important field of research. Finding carbon sources that also result in the presence of a liquid phase susceptible of acting as a sintering aid before, during or after the formation of $\mathrm{MgB}_{2}$ may be an interesting strategy as suggested by the positive effect of $\mathrm{K}_{2} \mathrm{CO}_{3}$ additions on the low and high-field $j_{c}$ in $\mathrm{MgB}_{2}$ bulk samples [34].

In the present work, the effect of additions of methylene blue trihydrate $\left(\mathrm{C}_{16} \mathrm{H}_{18} \mathrm{ClN}_{3} \cdot 3 \mathrm{H}_{2} \mathrm{O}\right)$ on the formation and some superconducting properties of $\mathrm{MgB}_{2}$ is reported. This compound is an industrial 
dye that is rich in carbon and forms a liquid between $200^{\circ} \mathrm{C}$ and $450^{\circ} \mathrm{C}$ when heated in a non-oxidizing atmosphere [35]. Instead of simply evaporating upon melting like e.g. malonic acid [20]. It leaves, at $800^{\circ} \mathrm{C}$, a carbonaceous residue amounting to $\approx 37 \%$ of its original mass. It has also the advantages of being readily available and inexpensive.

\section{Experimental details}

The starting reagents consisted of elemental powders of Mg (Alfa Aesar, $99.8 \%$ purity) and amorphous boron (Aldrich, 95-97 \%) as well as methylene blue trihydrate powder with $\mathrm{C}_{16} \mathrm{H}_{18} \mathrm{ClN}_{3} \cdot 3 \mathrm{H}_{2} \mathrm{O}$ composition (Alfa Aesar, assay $100.4 \%$ ). The powders were mixed in a mechanical blender (Bachofen, type T2C). Samples with $\mathrm{MgB}_{2}$ : Methylene blue trihydrate weight ratios of $1: \mathrm{y}$ with $0.0000 \leq \mathrm{y} \leq 0.0125$ with $(\Delta \mathrm{y}=0.0025)$ were prepared. A slight excess of $\mathrm{B}$ powder (corresponding to 2 at.\% of the nominal B stoichiometry) was added to compensate for the impurities, including some $\mathrm{Mg}$, present in the B commercial powder used for the present work, based on a previous optimization study [36]. The mixed powders were pressed into pellets with $12 \mathrm{~mm}$ diameter and $1.5 \mathrm{~mm}$ thickness under a pressure of $1.8 \mathrm{kbar}$. The pellets were reacted at $800^{\circ} \mathrm{C}$ for 1 $\mathrm{h}$ under Ar atmosphere with a heating rate of $100^{\circ} \mathrm{C} / \mathrm{h}$ and furnace cooling at the end of the treatment. To avoid oxidation by the residual $\mathrm{O}_{2}(<0.5 \mathrm{ppm})$ present in the Ar gas, the pellets were wrapped into Ti foils (Alfa Aesar, $99.7 \%, 32 \mu \mathrm{m}$ thickness) acting as oxygen getters and at the same time inhibiting Mg evaporation.

After reaction, the pellets were cut with a diamond saw. XRD patterns were recorded in a Bruker X-ray diffractometer with $\mathrm{CuK} \alpha$ radiation $(\lambda=1.5406 \AA)$ on one piece that was crushed into powder, first without and then again after mixing with silicon powder (Alfa Aesar, 99.999\%) used as an internal standard for lattice parameters calculations. These were performed with the UnitCell least square refinement programme [37]. The bulk density $(\rho)$ was estimated by dividing the sample mass by its volume. The microstructure was investigated in a TM3000 table-top scanning electron 
microscope (SEM) from HITACHI equipped with a QUANTAX 70 EDS analyser, on pieces of each sample composition that were cast into epoxy resin and polished with abrasive suspensions down to $0.25 \mu \mathrm{m}$ particle size. For magnetic measurements, bars with dimensions $8.0 \times 2.0 \times 1.5 \mathrm{~mm}^{3}$ were cut in the middle of the reacted pellets. The superconducting critical temperature $\left(T_{c}\right)$ was determined as the mid-point of the diamagnetic transition measured by means of a vibrating sample magnetometer (VSM) in a CRYOGENIC Ltd Mini-CFMS under a magnetic field $(B)$ of $5 \mathrm{mT}$ applied parallel to the longest axis of the samples in zero field cooling conditions. The critical current density $\left(j_{c}\right)$ was calculated using the Bean model from magnetisation hysteresis loops that were recorded on the same samples also with the magnetic field parallel to the long axis. The penetration field $\left(H_{\mathrm{p}}\right)$ has been estimated based on the initial magnetization branch of the $\mathrm{M}-\mathrm{H}$ loops as the applied field at which the M-H dependence departs from a linear relation. The trace element content of the starting boron powder was determined by means of X-ray fluorescence (XRF) measurements with an ARL 9400 XP sequential WD-XRF spectrometer equipped with a Rh anode. All peak intensity data were collected in vacuum. The elemental composition of the starting magnesium powder was analysed using X-ray photoelectron spectroscopy (XPS) using ESCAProbe $\mathrm{P}$ apparatus (Omicron Nanotechnology Ltd.) with a monochromatized Al anode X-ray source. Step size for survey spectra was 0.5 and $0.2 \mathrm{eV}$ for detail spectra. Size of the analyzed area was approximately $1 \mathrm{~mm}^{2} .5 \mathrm{keV} \mathrm{Ar}$ ions were used for depth profiling. Spectra evaluation was carried out by CasaXPS program.

\section{Results}

Figure 1 contains the XRD patterns of the samples after reaction at $800^{\circ} \mathrm{C}$. It can be seen that $\mathrm{MgB}_{2}$ is the majority phase notwithstanding the amount of methylene blue trihydrate added in the starting composition. Besides a little amount of $\mathrm{MgO}$ evidenced by a reflection at $2 \theta \approx 62.3^{\circ}$, very low intensity peaks due to unreacted $\mathrm{Mg}$ are visible. The intensity of the $\mathrm{MgO}$ peak is not significantly increasing with increasing levels of the additive. This is consistent with the relatively low oxygen 
content of methylene blue trihydrate in comparison with some other additives that have been tested as carbon sources for doping in $\mathrm{MgB}_{2}$, e.g. $\mathrm{K}_{2} \mathrm{CO}_{3}$ [34], malonic acid [20] or succinic acid [38], in which cases the amount of $\mathrm{MgO}$ impurity was clearly increasing with doping level. This indicates that the oxygen atoms present in methylene blue trihydrate, which are released below $200^{\circ} \mathrm{C}$ in the form of water vapor [35], do not react with the $\mathrm{Mg}$ powder particles. The presence of $\mathrm{MgO}$ in all samples can be partially due to the traces of MgO detected by XPS on the surface of the starting magnesium powder. The a- and c-axis lattice parameters of the $\mathrm{MgB}_{2}$ phase are plotted in Figure 2 and reported in Table 1. The addition of methylene blue trihydrate results in a clear decrease of the a-axis parameter, whereas the c-axis length hardly increases and even this tendency is within the standard deviation. Similar observations use to be reported when carbon is substituted for boron in the $\mathrm{MgB}_{2}$ lattice [14-16,20,31,34] The variation of the a-axis parameter can be used for estimating the actual amount of carbon that has entered the $\mathrm{MgB}_{2}$ phase by comparison with the data reported by Lee et al. [39] for a series of C-substituted $\mathrm{MgB}_{2}$ single crystals. The values, expressed as $\mathrm{x}$ in $\mathrm{MgB}_{2-\mathrm{x}} \mathrm{C}_{\mathrm{x}}$ for all samples are listed in Table $1\left(C_{X R D}\right)$, where they can be compared to a theoretical maximum value $\left(C_{n o m}\right)$ calculated by assuming full substitution of the nominal carbon content in the samples. Both values are rather close, indicating that most of the carbon atoms included in the methylene blue trihydrate additive have been introduced into the $\mathrm{MgB}_{2}$ lattice. The full width at half maximum (FWHM) of the $\mathrm{MgB}_{2}(002)$ and (110) XRD peaks were evaluated by fitting to a pseudoVoigt function. These values are also presented in Table 1. While a slight increase is observed for both as soon as some methylene blue trihydrate is added in the samples, the FWHM remains then constant up to $1 \mathrm{wt} . \%$ addition, before starting to increase significantly. Usually, carbon doping in $\mathrm{MgB}_{2}$ induces a progressive broadening of the XRD reflections [13,16]. In the present case, it seems that some mechanism counterbalances the degradation of crystallinity and/or the increase of residual strain that result from carbon incorporation into the $\mathrm{MgB}_{2}$ lattice. An effect of the same kind was 
recently observed for $\mathrm{K}_{2} \mathrm{CO}_{3}$ additions, although the FWMH even slightly decreased for low additive amounts in that case. Nevertheless, the broadening effect due to carbon substitution becomes preponderant at higher concentrations.

SEM images of polished cross-sections of the reacted pellets are shown in Fig.3. The microstructure of the undoped sample is characterized by a matrix made of small $(<1 \mu \mathrm{m})$ grains consisting of $\mathrm{MgB}_{2}$ (light grey in Fig. 3a) and large, generally elongated lumps (dark grey in Fig 3a). A few grains with low aspect ratio and intermediate grey contrast also appear. These were found to have $\mathrm{MgB}_{7}$ and $\mathrm{MgB}_{4}$ compositions respectively. These phases were not detected in the XRD patterns due to the low scattering power of boron. Some elongated cracks can be seen within the $\mathrm{MgB}_{2}$ matrix (e.g. arrow in Fig. 3a), besides a more refined porosity that can be distinguished as black spots with diameters lower than $3 \mu \mathrm{m}$. In the sample with 0.25 wt. $\%$ methylene blue trihydrate addition, the $\mathrm{MgB}_{2}$ matrix looks denser. In contrast, the large, elongated grain locations are often found to contain hollow areas (Fig. 3b). This tendency increases when more methylene blue trihydrate is added in the initial powder mixture and the $\mathrm{MgB}_{2}$ matrix deteriorates with the development of porosity, which becomes most obvious in the sample with 1.25 wt.\% methylene blue trihydrate addition (Fig. 3f). Methylene blue trihydrate forms a molten phase between $200^{\circ} \mathrm{C}$ and $450^{\circ} \mathrm{C}$, and releases about $40 \%$ of its mass in the form of gaseous species in the same temperature interval [35]. Antagonist effects are expected from these two phenomena. Gas evolution tends to induce porosity, whereas a liquid phase is likely to increase the bulk ceramic density by filling pores. The SEM micrographs indicate that the latter effect plays a major role for large amounts of additive. In contrast, the beneficial effect of the liquid phase towards increasing the bulk density seems preponderant at low addition levels, as further illustrated by the slight increase of $\rho$ for 0.25 to $1.00 \mathrm{wt} . \%$ addition (Table 1 ). The somehow lower $\rho$ value for the 0.50 wt.\% sample compared to the 0.25 and $0.75 \mathrm{wt} . \%$ samples could simply be due to a little difference in the initial packing density. 

performed by means of EDS on the polished cross section of the sample with $1.25 \mathrm{wt} . \%$ additive to check for the presence of these three elements after reaction. The results of a large area measurement $\left(2 \mathrm{~mm}^{2}\right)$ reveal that $\mathrm{N}$ is absent from this sample, indicating that it has been lost during the reaction process. In contrast, $\mathrm{Cl}$ can be identified, meaning that a part at least of the initial content of this element is still present. This is an interesting observation considering the fact that the thermal decomposition residue of methylene blue at $800^{\circ} \mathrm{C}$ contains some $\mathrm{N}$ beside $\mathrm{C}$ but no $\mathrm{Cl}$, the latter element escaping below $300^{\circ} \mathrm{C}$ in the form of $\mathrm{HCl}$ [35]. This means that $\mathrm{HCl}$ is likely to react with either $\mathrm{Mg}$ or $\mathrm{B}$ to trap the chlorine atoms up to $800^{\circ} \mathrm{C}$. The most probable mechanism is a reaction with $\mathrm{Mg}$ in the form of $\mathrm{MgO}$ that is present in the starting $\mathrm{Mg}$ powder [40]. Moreover, boron halides are not thermally stable enough to be formed at a temperature of $800^{\circ} \mathrm{C}$. The location of $\mathrm{Cl}$ in the microstructure could unfortunately not be identified due to its low amount. Attempts at doping $\mathrm{Cl}$ in $\mathrm{MgB}_{2}$ haven't been reported so far, so that it is difficult to estimate its contribution to the evolution of the lattice parameters and superconducting properties of $\mathrm{MgB}_{2}$ in case $\mathrm{Cl}$ is actually introduced in the lattice. However, since the $\mathrm{C}: \mathrm{Cl}$ atomic ratio in methylene blue trihydrate is $16: 1$, it can be assumed that $\mathrm{Cl}$ does not play a significant role compared to the effect of $\mathrm{C}$ doping. The EDS spectrum in Fig.4 (inset) shows a few other peaks emerging from the background. The presence of

$\mathrm{Ca}, \mathrm{K}, \mathrm{Si}$ and $\mathrm{Fe}$ can be traced back to the impurities present in the starting $\mathrm{Mg}$ powder (for $\mathrm{Ca}$ ) and B powder (for $\mathrm{Si}, \mathrm{K}$ and $\mathrm{Fe}$ ), with levels corresponding to $300,880 \mathrm{ppm}, 2770 \mathrm{ppm}$ and $250 \mathrm{ppm}$ at.\% respectively. Concerning the traces of sulfur revealed by the EDS spectrum, its origin is unclear. It may be a remnant of the methylene blue trihydrate decomposition or come from the $\mathrm{Mg}$ precursor powder (300 ppm). Its amount in the B powders is however negligible. mode, are plotted in Figure 5 for all samples after normalization to the magnetization value at $5 \mathrm{~K}$. 
$T_{c}$, also reported in Table 1, decreases monotonously with the increase of the methylene blue addition level. Following again the data published by Lee et al. [39], the $T_{c}$ of the samples can be used to estimate the amount of carbon doped in the $\mathrm{MgB}_{2}$ phase. The values are listed in Table $1\left(C_{T c}\right)$ and confirm those that were estimated based on the a-axis parameter variations and are thus again close to the maximum substitution level possible considering the nominal $\mathrm{C}$ content available in the methylene blue trihydrate additive $\left(C_{n o m}\right)$. This allows concluding that methylene blue trihydrate is an efficient carbon source as nearly all the carbon is doped into the superconductor. The overall reaction taking place in the powder mixture is however difficult to determine in view of the intricate thermal decomposition process of methylene blue trihydrate and because its potential interactions, as well as those of its decomposition products, with $\mathrm{Mg}$ or B are not known.

The occurrence of a liquid phase between $200^{\circ} \mathrm{C}$ and $450^{\circ} \mathrm{C}$ [35] can help ensuring the homogeneous distribution of $\mathrm{C}$ in the samples. Thus the increase of the FWHM of the $\mathrm{MgB}_{2} \mathrm{XRD}$ peaks, which usually results from $\mathrm{C}$ doping, is minimized at least for the lowest doping levels. Inhomogeneous distribution of carbon in $\mathrm{MgB}_{2}$ tends to increase the superconducting transition width [41]. The suppression of $\Delta T_{c}$ increase for low initial methylene blue trihydrate contents (Table 1) also indicates a good homogeneity of carbon distribution in the $\mathrm{MgB}_{2}$ matrix.

Figure 6 shows the $j_{c}(B)$ dependence calculated from magnetization hysteresis loops using the Bean model on all samples for measurements conducted at $35 \mathrm{~K}, 30 \mathrm{~K}, 25 \mathrm{~K}, 20 \mathrm{~K}$ and $15 \mathrm{~K}$. At $35 \mathrm{~K}$, i.e. rather close to $T_{c}$ for the compositions with the highest methylene blue trihydrate initial content, $j_{c}$ is lower in all doped samples. However, at $30 \mathrm{~K}$, the samples with 0.25 and $0.50 \mathrm{wt} . \%$ methylene blue trihydrate already have a higher low field $\mathrm{j}_{\mathrm{c}}$ than the pure sample, which however still exhibits better performance above $0.7 \mathrm{~T}$. At lower temperatures, the $j_{c}$ of the samples with methylene blue trihydrate additions tends to become significantly higher by comparison with that of the undoped sample. The 
best $j_{c}$ performance is observed in the $\mathrm{x}=0.50 \mathrm{wt} . \%$ sample at $25 \mathrm{~K}$, but at lower temperatures 1.00 wt.\% addition yields the best results.

The pinning force $\left(F_{p}=j_{c} \cdot B\right)$ is plotted in Fig.7 for measurements performed at $30 \mathrm{~K}$ and $20 \mathrm{~K}$. The $F_{p}(B)$ data for $35 \mathrm{~K}, 25 \mathrm{~K}$ and $15 \mathrm{~K}$ can be seen in Fig.S2. The behavior of $F_{p}(B)$ is qualitatively similar to that of $j_{c}(B)$. For $T$ close to $T_{c}, F_{p}(B)$ is larger in the undoped sample for the whole applied magnetic field range. However, below $30 \mathrm{~K}$, the $F_{p}(B)$ of the doped samples becomes clearly higher than without methylene blue trihydrate additions. Here again, the sample with $0.50 \mathrm{wt} . \%$ addition shows the highest value at $25 \mathrm{~K}$ but is superseded by the sample with $1.00 \mathrm{wt} \%$ at lower temperatures.

The normalized pinning force $\left(f=F_{p} / F_{p m a x}\right)$, i.e. the pinning force $F_{p}(B)$ normalized by the maximum value of $F_{p}\left(=F_{p \max }\right)$ is shown in Fig. 8 for all samples at $30 \mathrm{~K}$ and $20 \mathrm{~K}$ as a function of $b$ $204=B / B_{F p m a x}$ i.e. the applied magnetic field $B$ normalized by the field corresponding to $F_{p m a x}$. The $f(b)$ 205 data for measurements conducted at $35 \mathrm{~K}, 25 \mathrm{~K}$ and $15 \mathrm{~K}$ can be found in Fig.S3. The models corresponding to surface pinning (1), normal point pinning (2) and $\Delta \kappa$ pinning (3) [42] were used to evaluate the data and gain some insight into the dominant flux pinning mechanisms at play in the samples:

$$
f(b)=\frac{25}{16} \sqrt{b}\left(1-\frac{b}{5}\right)^{2}
$$

$$
f(b)=\frac{9}{4} b\left(1-\frac{b}{3}\right)^{2}
$$

$$
f(b)=3 b^{2}\left(1-\frac{2 b}{3}\right)
$$


In the low applied magnetic field range, i.e. $\mathrm{b} \leq 1$, all $f(b)$ curves are superimposed and hence demonstrate a similar flux pinning behavior notwithstanding of temperature or composition. The experimental data are situated between the predictions of the point pinning and $\Delta \kappa$ pinning models, so that it may be deduced that both types of pinning contribute to the observed $f(b)$ dependence. However, point pinning seems to account for the largest contribution. In contrast, for $f(b)>1$, the addition of methylene blue trihydrate results in a shift towards the surface pinning behavior, which however becomes less pronounced as the temperature decreases, so that at $15 \mathrm{~K}$ all samples behave in a similar way again. An upwards shift of the $f(b)$ curves at $b>1$ has already been observed several times in relation to carbon doping in $\mathrm{MgB}_{2}[19,34,43-46]$. The fact that this effect tends to be cancelled at low temperatures was not mentioned earlier. One may however question the conclusion that the upwards shift of the $f(b)$ curves above $b=1$ for T close to $T_{c}$ really reflects a change in the flux pinning mechanism. In fact, as the applied field approaches the irreversibility field, the induced superconducting current may not flow around the whole circumference of the sample anymore. Since the sample size was assumed to be the length scale of the induced current for all measurement conditions, $j_{\mathrm{c}}(B)$ and thus $F(B)$ as well as $f(b)$ may not be accurately estimated at the highest temperatures and/or fields thereby leading to artefacts. Since $j_{\mathrm{c}}$ depends on $\mathrm{H}$, the application of the Bean model is in general only valid for $H$ larger than the penetration field $\left(H_{p}\right)$. For $H<H_{p}, j_{c}$ will be overestimated, especially when the field is applied parallel to the long axis of the sample [47]. This effect might be significant for the analysis of the normalized $F_{p}$ data at $b<1$ if $H_{p}$ is close to $B_{F p m a x}$. The $H_{p}$ values for all samples at various temperatures are listed in Table S1. Although they are larger than those previously reported for $\mathrm{MgB}_{2}$ single crystals [48], comparison with the $F_{p}$ versus $B$ data in Fig.7 and Fig.S2 show that they are significantly lower than $B_{F p m a x}$ for all samples and temperatures. The influence of this effect on the analysis of the flux pinning mechanism at $b<1$ is therefore limited to the very beginning of the $f(b)-b$ curves and does not invalidate the conclusions. 
While methylene blue trihydrate additions have a beneficial influence on $j_{c}$ in self field, contrary to many other carbon doping sources, it has no influence on the flux pinning mechanism under low applied fields, even if the absolute value of $F_{p}$ is increased. This shows that the low-field and selffield $j_{c}$ enhancement is not due to fundamental modifications of the flux pinning landscape. The fact that methylene blue trihydrate forms a molten phase between $200^{\circ} \mathrm{C}$ and $450^{\circ} \mathrm{C}$ might be playing a role. Although solidification of the solid residue takes place well below the onset temperature of $\mathrm{MgB}_{2}$ formation [49], a transient liquid phase can act on the microstructure of the $\mathrm{Mg}-\mathrm{B}$ powder mixture during the temperature ramp up. A similar effect was assumed for explaining the effect of $\mathrm{K}_{2} \mathrm{CO}_{3}$ additions [34] but in the present case the self-field $j_{c}$ increase at $15 \mathrm{~K}$ reaches $22 \%$ versus 12 $\%$ for $\mathrm{K}_{2} \mathrm{CO}_{3}$. A liquid phase forming at relatively low temperatures acts differently from metallic additives that induce melting in contact with $\mathrm{Mg}$ due to the occurrence of an eutectic structure in some binary phase diagrams [50-57], in which case the liquid is present during the $\mathrm{MgB}_{2}$ formation process. A prospective route for further improving the superconducting performance of $\mathrm{MgB}_{2}$ could consist in combining additives that may result in carbon doping while transient liquid phases are available during temperature ramp up and while the $\mathrm{MgB}_{2}$ phase is forming.

\section{Conclusions}

The present results demonstrate that methylene blue trihydrate $\left(\mathrm{C}_{16} \mathrm{H}_{18} \mathrm{ClN}_{3} \cdot 3 \mathrm{H}_{2} \mathrm{O}\right)$, a cheap and readily available chemical used as an industrial dyestuff, is an efficient source of carbon atoms in view of doping in the $\mathrm{MgB}_{2}$ lattice using the in-situ synthesis route as approximately all the carbon atoms from methylene blue trihydrate end up in the $\mathrm{MgB}_{2}$ phase considering lattice parameters and $\mathrm{T}_{\mathrm{c}}$ variations. While the carbon atoms originating from the additive are introduced in $\mathrm{MgB}_{2}$, nitrogen was not detected by EDS measurements after reaction. On the other hand, some sulfur and chlorine were found, although at a trace impurity level so that their exact location in the sample could not be ascertained. Nevertheless, since no report dealing with sulfur or chlorine doping in $\mathrm{MgB}_{2}$ seem to 
have been published yet, it would be interesting to investigate their possible individual effects as they

261 might be incorporated in the lattice of the superconducting phase. At $35 \mathrm{~K}$, the $j_{c}(B)$ performance of

262 the undoped sample as well as its pinning force are the highest. However, doping induces clear 263 improvements for $\mathrm{T}<30 \mathrm{~K}$, with the best results achieved for $1.00 \mathrm{wt} . \%$ methylene blue trihydrate 264 addition, an amount that is at least one order of magnitude smaller than for most other organic 265 compounds reported as carbon sources up to now. Attempts at using methylene blue trihydrate as an 266 additive for manufacturing $\mathrm{MgB}_{2}$ wires could be interesting, however in that case, it would be 267 recommended to start from dehydrated methylene blue to avoid possible adverse effects during $\mathrm{H}_{2} \mathrm{O}$ 268 release inside the metallic sheath.

269 Acknowledgements

270 Mr. Henrik Paulsen is gratefully acknowledged for preparing the polished cross-sections of the 271 samples for SEM investigations.

272

273 


\section{References}

[1] D.A. Abin, N.A. Mineev, M.A. Osipov, S.V. Pokrovskii and I.A. Rudnev, Dry cryomagnetic system with $\mathrm{MgB}_{2}$ coil, J, Phys. Conf. Ser. 941 (2017) 012056

[2] J. Liu, H. Ma, L. Huang and P. Ju, Research on an axial Maglev device with primary superconductive coils for a 1000 MW hydraulic generator set, IEEE Trans. Appl. Supercond. 27 (2017) 5000106

[3] S. Mizuno, T. Yagai, T. Okubo, S. Mizuochi, M. Kamibayashi, M. Jinbo, T. Takao, Y. Makida, T. Shintomi, N. Hirano, T. Komagome, K. Tsukada, Y. Onji, Y. Arai, M. Tomita, D. Miyagi, M. Tsuda and T. Hamajima, Feasibility study of $\mathrm{MgB}_{2}$ cable for pancake coil of energy storage device, IEEE Trans. Appl. Supercond. Accepted for publication, DOI 10.1109/TASC.2018.2794334 [4] A. Morandi, A. Anemona, G. Angeli, M. Breschi, A. Della Corte, C. Ferdeghini, C. Gandolfi, G. Grandi, G. Grasso, L. Martini, U. Melaccio, D. Nardelli, P.L. Ribani, S. Siri, M. Troppeano, S. Turtù and M. Vignolo, The DRYSMES4GRID project: Development of a $500 \mathrm{~kJ} / 200 \mathrm{~kW}$ cryogen-free cooled SMES demonstrator based on $\mathrm{MgB}_{2}$, IEEE Trans. Appl. Supercond. 28 (2018) 5700205

[5] K. Konstantopoulou, A. Ballarino, A. Gharib, A. Stimac, M. Garcia Gonzalez, A.T. Perez Fontenla and M. Sugano, Electro-mechanical characterization of $\mathrm{MgB}_{2}$ wires for the superconducting link project at CERN, Supercond. Sci. Technol. 29 (2016) 084005

[6] F. Karaboga, H. Yetis, M. Akdogan, D. Gajda and I. Belenli, Design, fabrication, and testing of $\mathrm{MgB}_{2} / \mathrm{Fe}$ racetrack coil, IEEE Trans. Appl. Supercond. 28 (2018) 6200805

[7] J. Wang, Y. Bugoslavsky, A. Berenov, L. Cowey, A.D. Caplin, L.F. Cohen, L.D. Cooley, X. Song and D.C. Larbalestier, High critical current density and improved irreversibility field in bulk $\mathrm{MgB}_{2}$ made by a scalable, nanoparticle addition route, Appl. Phys. Lett. 81 (2002) 2026 - 2028

[8] G.J. Xu, J.-C. Grivel, A.B. Abrahamsen and N.H. Andersen, Enhancement of the irreversibility field in bulk $\mathrm{MgB}_{2}$ by $\mathrm{TiO}_{2}$ nanoparticle addition, Physica C 406 (2004) 95 - 99 
[9] E. Babic, N. Novosel, D. Pajic, S. Galic, K. Zadro and D. Drobac, Magnetic nanoparticles in

299

300

301

302

303

304

305

306

307

308

309

310

$\mathrm{MgB}_{2}$ : vortex pinning, pair breaking and connectivity, J. Magn. Magn. Mater. 400 (2016) 88 - 92

[10] D. Goto, T. Machi, Y. Zhao, N. Koshizuka, M. Murakami and S. Arai, Improvement of critical current density in $\mathrm{MgB}_{2}$ by Ti, Zr and Hf doping, Physica C 392 (2003) 272 - 275

[11] N. Novosel, S. Galic, D. Pajic, K. Zadro and E. Babic, Enhancing superconducting properties of $\mathrm{MgB}_{2}$ by addition of magnetic particles, J. Supercond. Nov. Magn. 28 (2015) 425 - 430

[12] M.G. Babaoglu, S. Safran, Ö.Civek, H. Ail, E. Ertekin, Md. Shahriar, A. Hossein, E. Yanmaz and A. Gencer, Microstructural and superconducting properties of $\mathrm{C}_{6} \mathrm{H}_{6}$ added bulk $\mathrm{MgB}_{2}$ superconductor, J. Magn. Magn. Mater. 324 (2012) 3455 - 3459

[13] S.X. Dou, O. Shcherbakova, W.K. Yeoh, J.H. Kim, S. Soltanian, X.L. Wang, C. Senatore, R. Flükiger, M. Dhalle, O. Husnjak and E. Babic, Mechanism of enhancement in electromagnetic properties of $\mathrm{MgB}_{2}$ by nano SiC doping, Phys. Rev. Lett. 98 (2007) 097002

[14] S. Soltanian, J. Horvat, X.L. Wang, P. Munroe and S.X. Dou, Effect of nano-carbon particle doping on the flux pinning properties of $\mathrm{MgB}_{2}$ superconductor, Physica C 390 (2003) 185 - 190

[15] C.H. Cheng, H. Zhang, Y. Zhao, Y. Feng, X.F. Rui, P. Munroe, H.M. Zeng, N. Koshizuka and M. Murakami, Doping effect of nano-diamond on superconductivity and flux pinning in $\mathrm{MgB}_{2}$, Supercond. Sci. Technol. 16 (2003) 1182 - 1186

[16] J.M. Parakkandy, M. Shahabuddin, M. Shahabuddin Shah, N.S. Alzayed, S.A.S. Qaid, N.M. Ramay and M.A. Shar, Effect of glucose doping on the $\mathrm{MgB}_{2}$ superconductors using cheap crystalline boron, Physica C 519 (2015) 137 - 141

[17] L.B.S. Da Silva, A.A. Vianna, A.L.R. Manesco, E.E. Hellstrom and D. Rodrigues Jr., The influence of stearic acid addition on the superconducting properties of $\mathrm{MgB}_{2}$, IEEE Trans. Appl. Supercond. 26 (2016) 7100204 
[18] J.H. Kim, S.X. Dou, M.S.A. Hossain, X. Xu, J.L. Wang, D.Q. Shi, T. Nakane and H. Kumakura, Systematic study of a $\mathrm{MgB}_{2}+\mathrm{C}_{4} \mathrm{H}_{6} \mathrm{O}_{5}$ superconductor prepared by the chemical solution route, Supercond. Sci. Technol. 20 (2007) 715 - 719

[19] Z. Gao, Y. Ma, X. Zhang, D. Wang, Z. Yu, K. Watanabe, H. Yang and H. Wen, Strongly enhanced critical current density in $\mathrm{MgB}_{2} / \mathrm{Fe}$ tapes by stearic acid and stearate doping, Supercond. Sci. Technol. 20 (2007) $485-489$

[20] C. Li, H. Suo, M. Liu, L. Ma, Y. Wang, M. Tian, B. Wan, J. Cui and Y. Ji, Effect of malonic acid and of different doping methods on the superconducting properties of $\mathrm{MgB}_{2}$ superconductors, Physica C 555 (2018) 60 - 65

[21] J.-C. Grivel, Influence of iridium doping in $\mathrm{MgB}_{2}$ superconducting wires, Physica C 547 (2018) $7-15$

[22] Y. Zhao, C. Ke, Y. Yang, C.C. Hsieh, D. Zhou, C. Cheng and Y. Zhang, $\mathrm{CrB}_{2}$ doping effects on critical current density and flux pinning of $\mathrm{MgB}_{2}$, IEEE Trans. Appl. Supercond. 29 (2019) 6200305 [23] J.-C. Grivel, A. Alexiou, S. Namazkar and A. Pitillas, Effect of platinum group metal doping in magnesium diboride wires, IEEE Trans. Appl. Supercond. 26 (2016) 6200505

[24] J.-C. Grivel, S. Namazkar, A. Alexiou and O.J. Holte, Preparation and characterization of Os doped $\mathrm{MgB}_{2}$, Physica C 507 (2014) 70 - 74

[25] J.C. Grivel and M. Burdusel, Preparation and characterization of Sc doped $\mathrm{MgB}_{2}$ wires, Physica C 528 (2016) $65-72$

[26] C.H. Cheng, Y. Yang, C. Ke and H.T. Lin, Iron doping effect on superconducting properties of $\mathrm{MgB}_{2}$, Physica C 470 (2010) 1092 - 1095

[27] B. Kang, M.-S. Park, H.-S. Lee, M.-H. Jung and S.-I. Lee, Comparison between Al and C substitutions in the upper critical field of $\mathrm{MgB}_{2}$ single crystals, J. Kor. Phys. Soc. 58 (2011) 498 - 502 
[28] J.Y. Xiang, D.N. Zheng, J.Q. Li, S.L Li, H.H Wen and Z.X.Zhao, Effects of Al doping on the superconducting and structural properties of $\mathrm{MgB}_{2}$, Physica C 386 (2003) 611-615

[29] G.J. Xu, J.-C. Grivel, A.B Abrahamsen, X.P. Chen and N.H. Andersen, Structure and superconductivity of double-doped $\mathrm{Mg}_{1-\mathrm{x}}\left(\mathrm{Al}_{0.5} \mathrm{Li}_{0.5}\right)_{\mathrm{x}} \mathrm{B}_{2}$, Physica C 399 (2003) 8-14

[30] G.J. Xu, J.-C. Grivel, A.B Abrahamsen, X.P. Chen and N.H. Andersen, Superconducting properties of $\mathrm{Zn}$ and $\mathrm{Al}$ double-doped $\mathrm{Mg}_{1-\mathrm{x}}\left(\mathrm{Zn}_{0.5} \mathrm{Al}_{0.5}\right)_{\mathrm{x}} \mathrm{B}_{2}$, Physica $\mathrm{C} 403(2004) 113-118$

[31] A.Yu. Potanin, D.Yu. Kovalev, E.A. Levashov, P.A. Loginov, E.I. Patsera, N.V. Shvyndina, K.S. Pervakov, V.A. Vlasenko and S.Yu. Gavrilkin, The features of combustion synthesis of aluminium and carbon doped magnesium diboride, Physica C 541 (2017) 1 - 9

[32] C. Laliena, E. Matínez, L. A. Angurel and R. Navarro, Effect of ball milling and fatty acid addition on the properties of $\mathrm{MgB}_{2}$ wires, IEEE Trans. Appl. Supercond. 25 (2015) 6200204

[33] D.N. Rakov, A.E. Vorobieva, P.V. Konovalov, E.V. Kotova, Yu.N. Belotelova and M.V. Polikarpova, Influence of carbon doping on $\mathrm{MgB}_{2}$ superconducting properties, Physics Proc. 36 (2012) $1480-1485$

[34] J.-C. Grivel, Critical current density improvements in $\mathrm{MgB}_{2}$ superconducting bulk samples by $\mathrm{K}_{2} \mathrm{CO}_{3}$ additions, Physica C 550 (2018) $1-6$

[35] J.-C. Grivel, Thermal stability and decomposition of methylene blue trihydrate, In preparation [36] J.C. Grivel, A. Alexiou, K. Rubešová, X. Tang, N.H. Andersen, M. von Zimmermann and A. Watenphul, Preparation and characterization of $\mathrm{Mg}_{1-\mathrm{x}} \mathrm{B}_{2}$ bulk samples and $\mathrm{Cu} / \mathrm{Nb}$ sheathed wires with low grade amorphous boron powder, J. Supercond. Nov. Magn. 27 (2014) 497-504

[37] T.J.B. Holland and S.A.T. Redfern, Unit cell refinement from powder diffraction data: The use of regression diagnostics, Mineral. Mag., 61 (1997) 65-77. 
[38] H. Agil, O. Cicek, E. Ertekin, A. Motaman, M.S.A. Hossain, S.X. Dou and A. Gencer, Effects of $\mathrm{MgO}$ on the electronic and superconducting properties in succinic acid $\left(\mathrm{C}_{4} \mathrm{H}_{6} \mathrm{O}_{4}\right)$ doped $\mathrm{MgB} 2$ bulks, J. Supercond. Nov. Magn. 26 (2013) 1525 - 1529

[39] S. Lee, M. Takahiko, A. Yamamoto, H. Uchiyama and S. Tajima, Carbon-substituted $\mathrm{MgB}_{2}$ single crystals, Physica C 397 (2003) 7 - 13

[40] Z. Zhang, X. Lu, S. Yang and F. Pan, Preparation of anhydrous magnesium chloride from magnesia, Industrial \& Engineering Chemistry Research 51 (2012) 9713 - 9718

[41] C. Senatore, P. Lezza, R. Lortz, O. Shcherbakova, W.K. Yeoh, S.X. Dou and R. Flükiger, Specific heat and magnetic relaxation analysis of $\mathrm{MgB}_{2}$ bulk samples with and without additives, IEEE Trans. Appl. Supercond. 17 (2007) 2941 - 2944

[42] T. Goto, K. Inagaki and K. Watanabe, Critical current density in filamentary (Nd, Sm, Eu, Gd) - $\mathrm{Ba}-\mathrm{Cu}-\mathrm{O}$ superconductors prepared by a solution spinning method, Physica C 330 (2000) 51 57

[43] S. Ueda, J.-I. Shimoyama, A. Yamamoto, S. Horii and K. Kishio, Enhanced critical current properties observed in $\mathrm{Na}_{2} \mathrm{CO}_{3}$-doped $\mathrm{MgB}_{2}$, Supercond. Sci. Technol. 17 (2004) 926 - 930

[44] J.L. Wang, R. Zeng, J.J. Kim, L. Lu and S.X. Dou, Effects of C substitution on the pinning mechanism of $\mathrm{MgB}_{2}$, Phys. Rev. B 77 (2008) 174501

[45] S.R. Ghorbani, M. Darini, X.L. Wang, M.S.A. Hossain and S.X. Dou, Vortex flux pinning mechanism and enhancement of in-field $\mathrm{j}_{\mathrm{c}}$ in succinic acid doped $\mathrm{MgB}_{2}$, Sol. State Commum. 168 (2013) $1-5$

[46] C.D. Wang, D.L. Wang, X.P. Zhang, C. Yao, C.L. Wang and Y.W. Ma, Aniline doping and high energy milling to greatly enhance electromagnetic properties of magnesium diboride superconductors, Physica C 489 (2013) 36 - 39 
[47] A. Sanchez and C. Navau, Critical-current density from magnetization loops of finite high- $\mathrm{T}_{\mathrm{c}}$ superconductors, Supercond. Sci. Technol. 14 (2001) 444 - 447

[48] A.D. Caplin, Y. Bugoslavsky, L.F. Cohen, L. Cowey, J. Driscoll, J. Moore and G.K. Perkins, Critical fields and critical currents in $\mathrm{MgB}_{2}$, Supercond. Sci. Technol. 16 (2003) 176 - 182

[49] J.-C. Grivel, R. Pinholt, N.H. Andersen, P. Kovac. I. Husek and J. Homeyer, In situ investigations of phase transformations in Fe-sheathed $\mathrm{MgB}_{2}$ wires, Supercond. Sci. Technol. 19 (2006) 96 - 101

[50] Y. Hishinuma, A. Kikuchi, K. Matsuda, K. Nishimura, Y. Kubota, S. Hata, S. Yamada and T. Takeuchi, Microstructure and superconducting properties of $\mathrm{Cu}$ addition $\mathrm{MgB}_{2}$ multifilamentary wires using boron isotope powder as the boron source material, Physics Procedia 36 (2012) 14861491

[51] J.-C. Grivel, Attempts at doping indium in $\mathrm{MgB}_{2}$, Physica C 531 (2016) 67 - 71

[52] P. Badica, G. Aldica, M. Burdusel and K. Endo, Composites of $\mathrm{MgB}_{2}$ with $\mathrm{Bi}_{2} \mathrm{O}_{3}, \mathrm{Bi}, \mathrm{Sb}_{2} \mathrm{O}_{3}$, or Sb obtained by ex-situ spark plasma sintering, Jpn. J. Appl. Phys. 51 (2012) 11PG13

[53] D. Batalu, G. Aldica, S. Popa, L. Miu, M. Enculescu, R.F. Negrea, I. Pasuk and P. Badica, High magnetic field enhancement of the critical current density by $\mathrm{Ge}, \mathrm{GeO}_{2}$ and $\mathrm{Ge}_{2} \mathrm{C}_{6} \mathrm{H}_{10} \mathrm{O}_{7}$ additions to $\mathrm{MgB}_{2}$, Scripta Materialia 82 (2014) $61-64$

[54] J. Huo, Y.C. Liu, Z.Z. Dong and H. Jiang, Effect of Sn-doping on the sintering process of $\mathrm{MgB}_{2}$ and its superconductive properties, J. Mater. Sci. Mater. Electron. 22 (2011) 233 - 237

[55] M. Kuhberger and G. Gritzner, Effects of Sn, Co and Fe on $\mathrm{MgB}_{2}$, Physica C 370 (2002) 39 - 43 [56] J.-C. Grivel, A. Abrahamsen and J. Bednarčik, Effects of Cu or Ag additions on the kinetics of $\mathrm{MgB}_{2}$ phase formation in Fe-sheathed wires, Supercond. Sci. Technol. 21 (2008) 035006

[57] J.-C. Grivel, N.H. Andersen, P.G.A.P. Pallewatta, Y. Zhao and M.v. Zimmermann, Influence of $\mathrm{Bi}$, Se and Te additions on the formation temperature of $\mathrm{MgB}_{2}$, Supercond. Sci. Technol. 25 (2012) 015010 


\section{Figure captions}

414 Figure 1: XRD patterns of the samples after reaction at $800^{\circ} \mathrm{C}$. The amount of methylene blue 415 trihydrate addition is indicated in wt.\% above the respective patterns. The Miller indices denote $\mathrm{MgB}_{2}$ 416 diffraction peaks. $\bullet \mathrm{MgO}, \bullet \mathrm{Mg}$.

417 Figure 2: Lattice parameters of the $\mathrm{MgB}_{2}$ phase versus nominal methylene blue trihydrate content.

418 Figure 3: SEM images (backscattering mode) of polished cross-sections of the samples with nominal 419 methylene blue trihydrate contents equal to 0.00 wt. \% (a); 0.25 wt. \% (b); 0.50 wt. \% (c), 0.75 wt. $420 \%$ (d), 1.00 wt. $\%$ and 1.25 wt. $\%$ (e), after reaction at $800^{\circ} \mathrm{C}$. The same magnification was used for 421 all images. The arrow in (a) shows an elongated crack.

422 Figure 4: EDS spectrum obtained from the polished cross-section of the sample with 1.25 wt.\% 423 nominal methylene blue trihydrate content. The inset shows a detail of the same spectrum.

424 Figure 5: VSM data showing the superconducting transition in reacted samples with various nominal 425 methylene blue trihydrate contents.

426 Figure 6: Critical current density $\left(j_{c}\right)$ at $35 \mathrm{~K}, 30 \mathrm{~K}, 25 \mathrm{~K}, 20 \mathrm{~K}$ and $15 \mathrm{~K}$ versus applied magnetic 427 field $(B)$ calculated with the Bean model using magnetization hysteresis loops. The nominal 428 methylene blue trihydrate content is indicated as wt.\%.

$429 \quad$ Figure 7: Pinning force $\left(F_{p}\right)$ at $30 \mathrm{~K}$ and $20 \mathrm{~K}$ versus applied magnetic field $(B)$ for samples with 430 various nominal methylene blue trihydrate contents indicated as wt.\%.

$431 \quad$ Figure 8: Normalized pinning force $f=F_{p} / F_{p \max }$ at $30 \mathrm{~K}$ and $20 \mathrm{~K}$ versus the normalized magnetic 432 field $b=B / B_{\text {Fpmax }}$. The data for the different nominal methylene blue trihydrate contents indicated as 433 wt.\%. are compared to theoretical predictions of three flux pinning mechanism models: surface 434 pinning (S), point pinning $(\mathrm{P})$ and $\Delta \kappa$ pinning $(\mathrm{K})$. 
437 Table captions

438 Table 1: $a$-axis and $c$-axis lattice parameters; bulk density $(\rho)$, critical temperature $\left(T_{c}\right)$ and transition

439 width $\left(\Delta T_{c}\right)(10 \%$ - $90 \%$ of the maximum diamagnetic signal); full width at half maximum (FWHM)

440 of the $\mathrm{MgB}_{2}(002)$ and (110) X-ray diffraction peaks; carbon content estimated from XRD data $\left(\mathrm{C}_{\mathrm{XRD}}\right)$

441 and $\mathrm{T}_{\mathrm{c}}$ values $\left(\mathrm{C}_{\mathrm{Tc}}\right)$ as well as theoretical maximum carbon doping level $\left(\mathrm{C}_{\mathrm{nom}}\right)$ of the $\operatorname{MgB} \mathrm{B}_{2}+\mathrm{x}$

$442 \mathrm{C}_{16} \mathrm{H}_{18} \mathrm{ClN}_{3} \cdot 3 \mathrm{H}_{2} \mathrm{O}$ samples after heat treatment at $800^{\circ} \mathrm{C}$.

443 


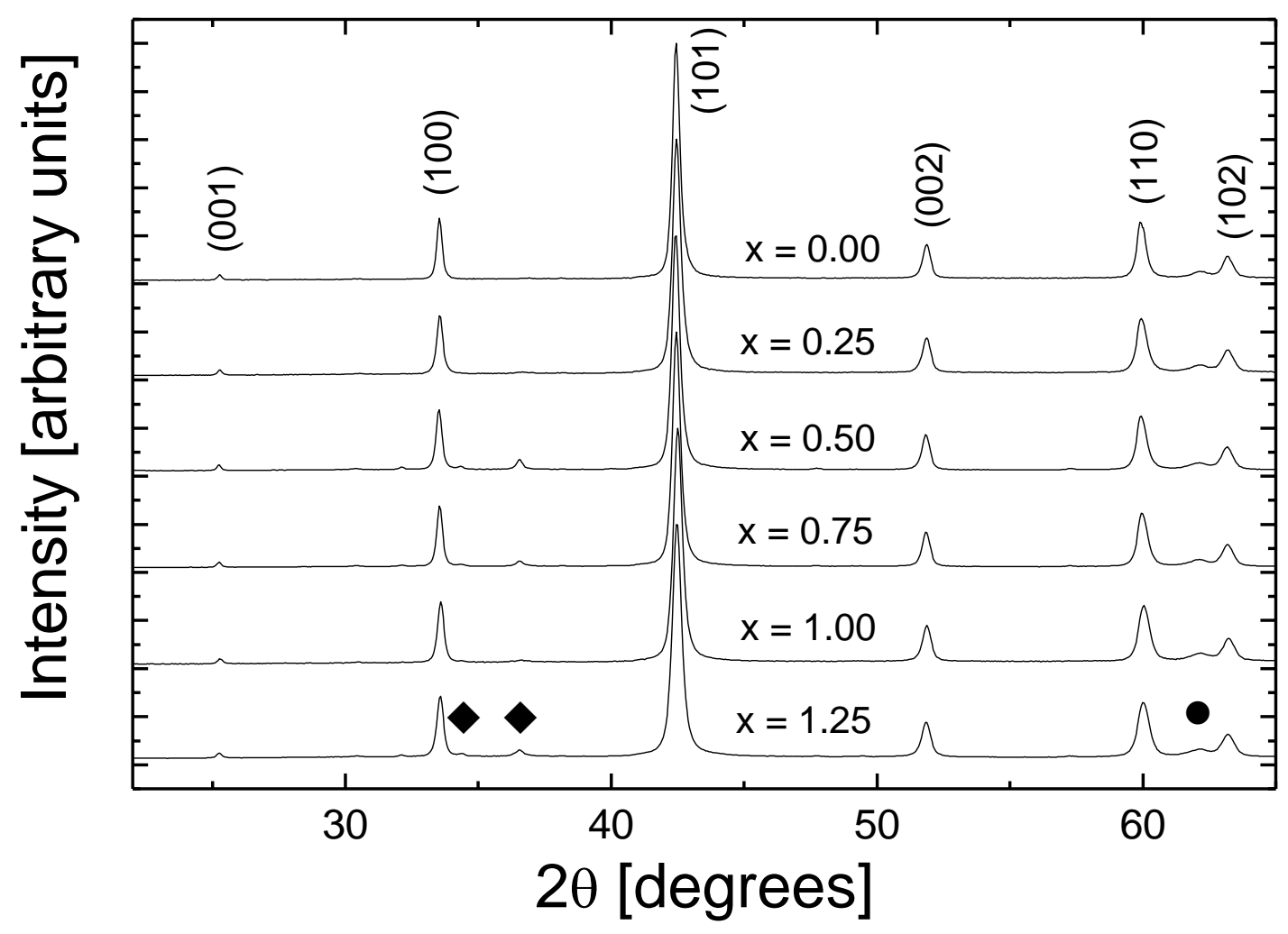

446

Figure 1 


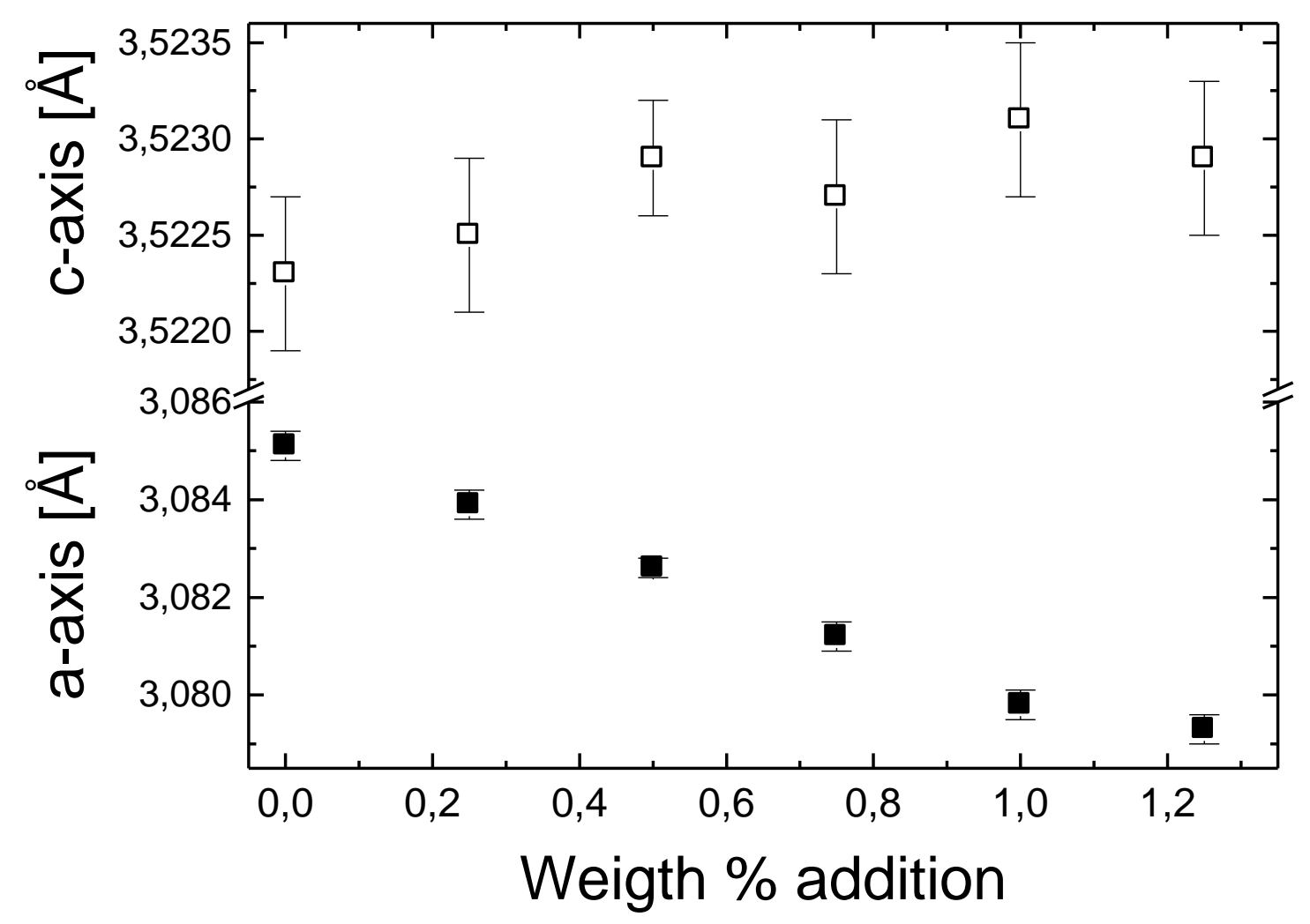

449

Figure 2

451

452

453

454

455

456

457

458

459

460 

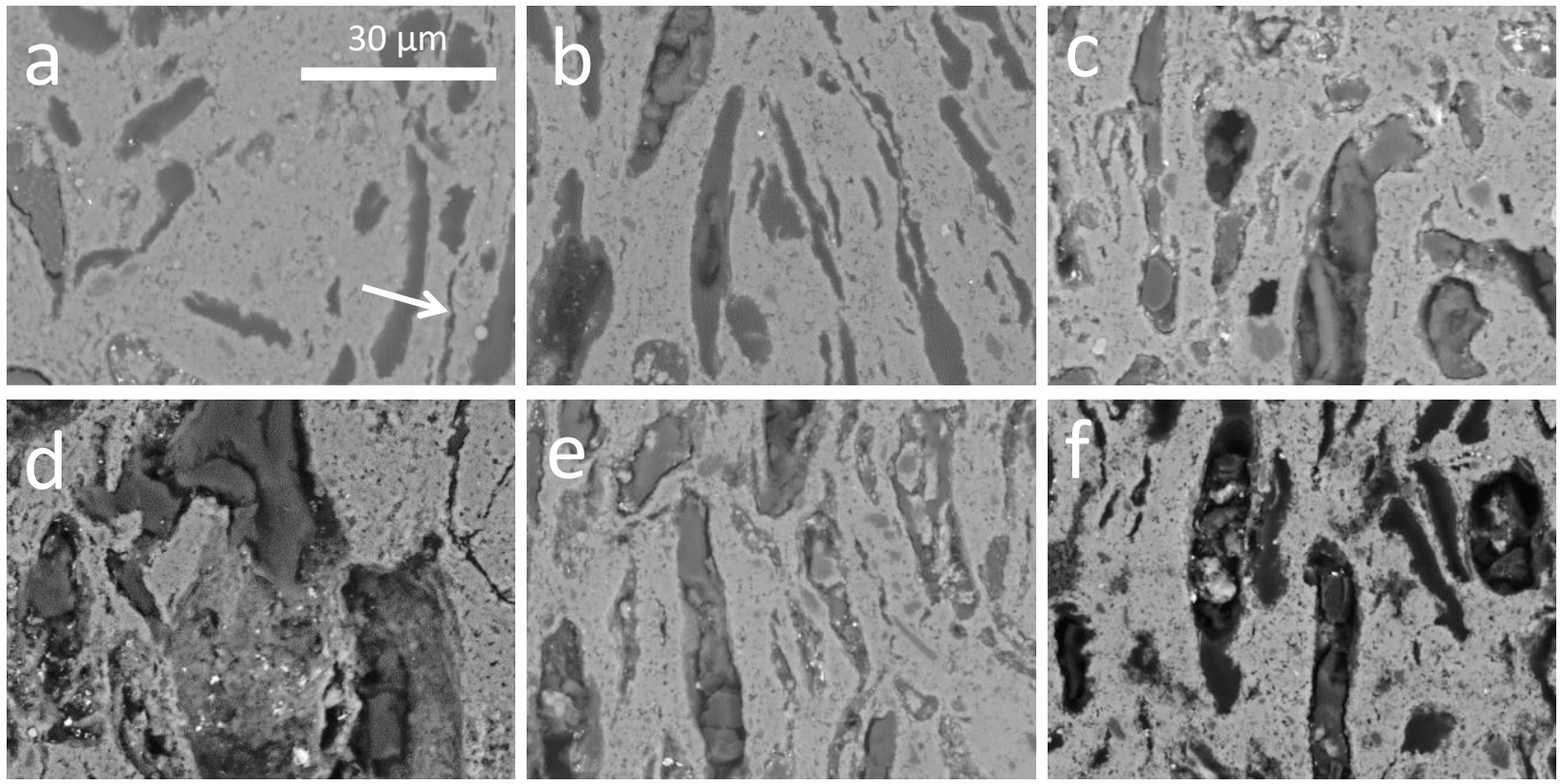

466

467

Figure 3

468 


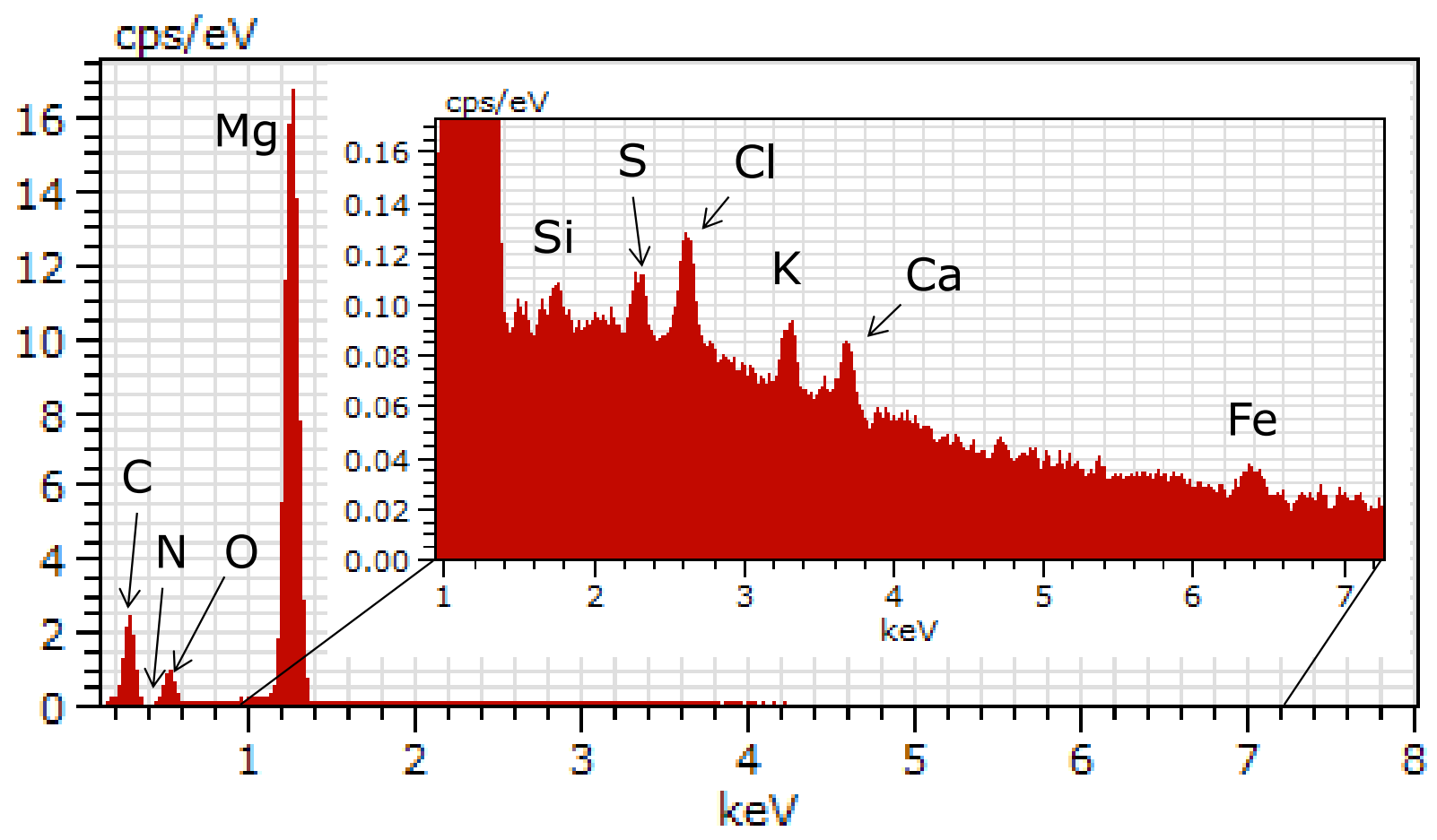

469

470

471

Figure 4

472 


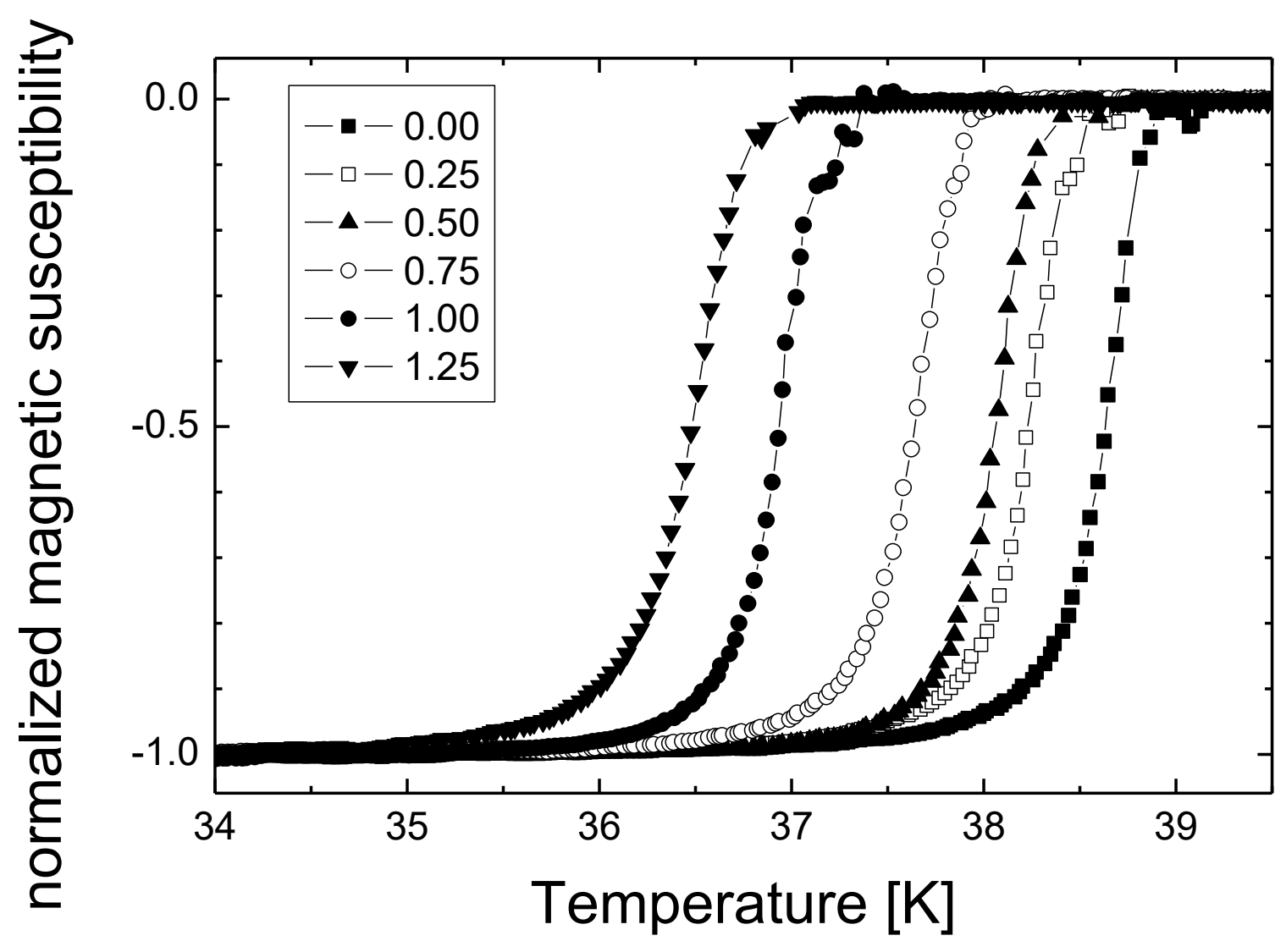

473

Figure 5 

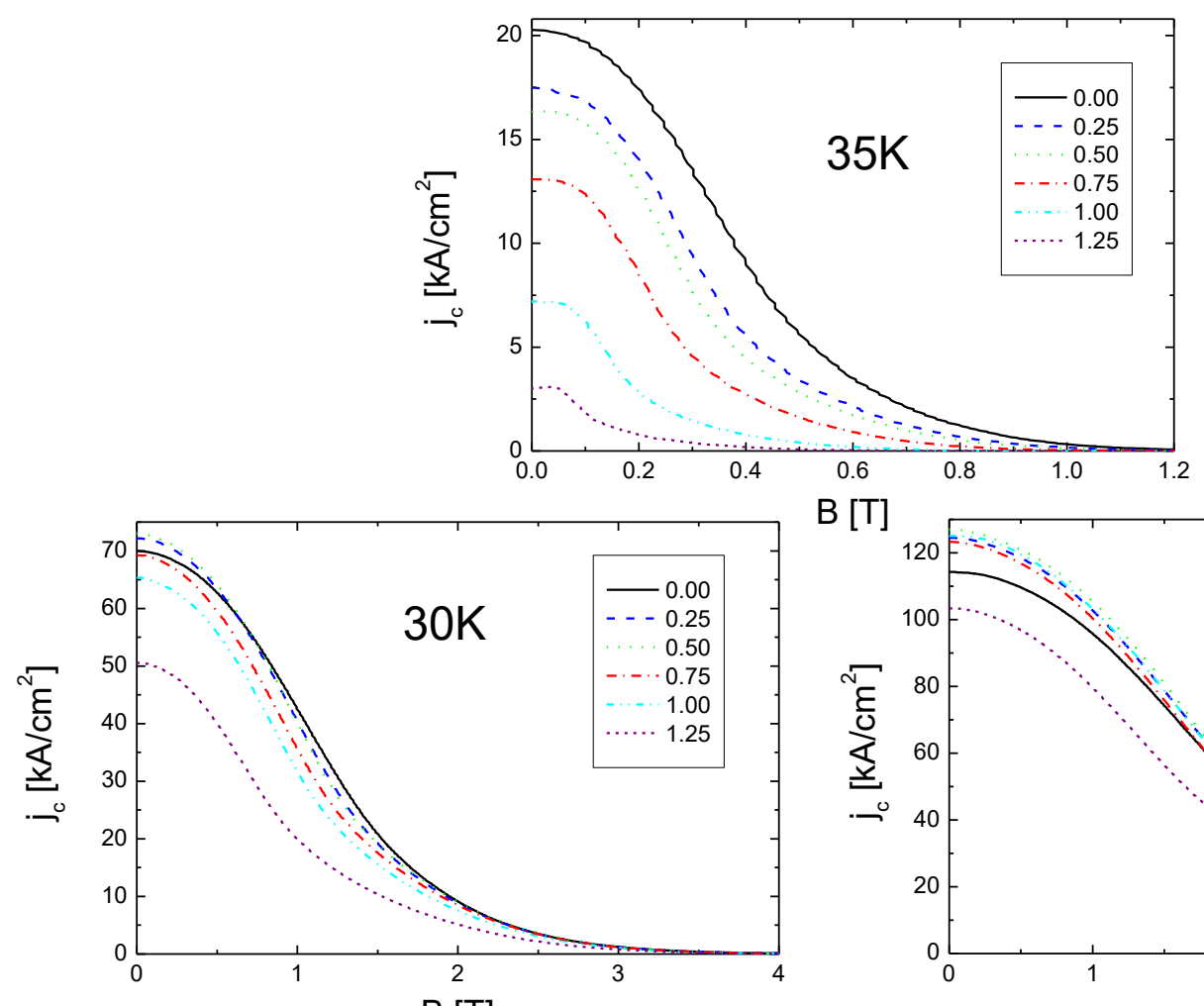

$B$ [T]
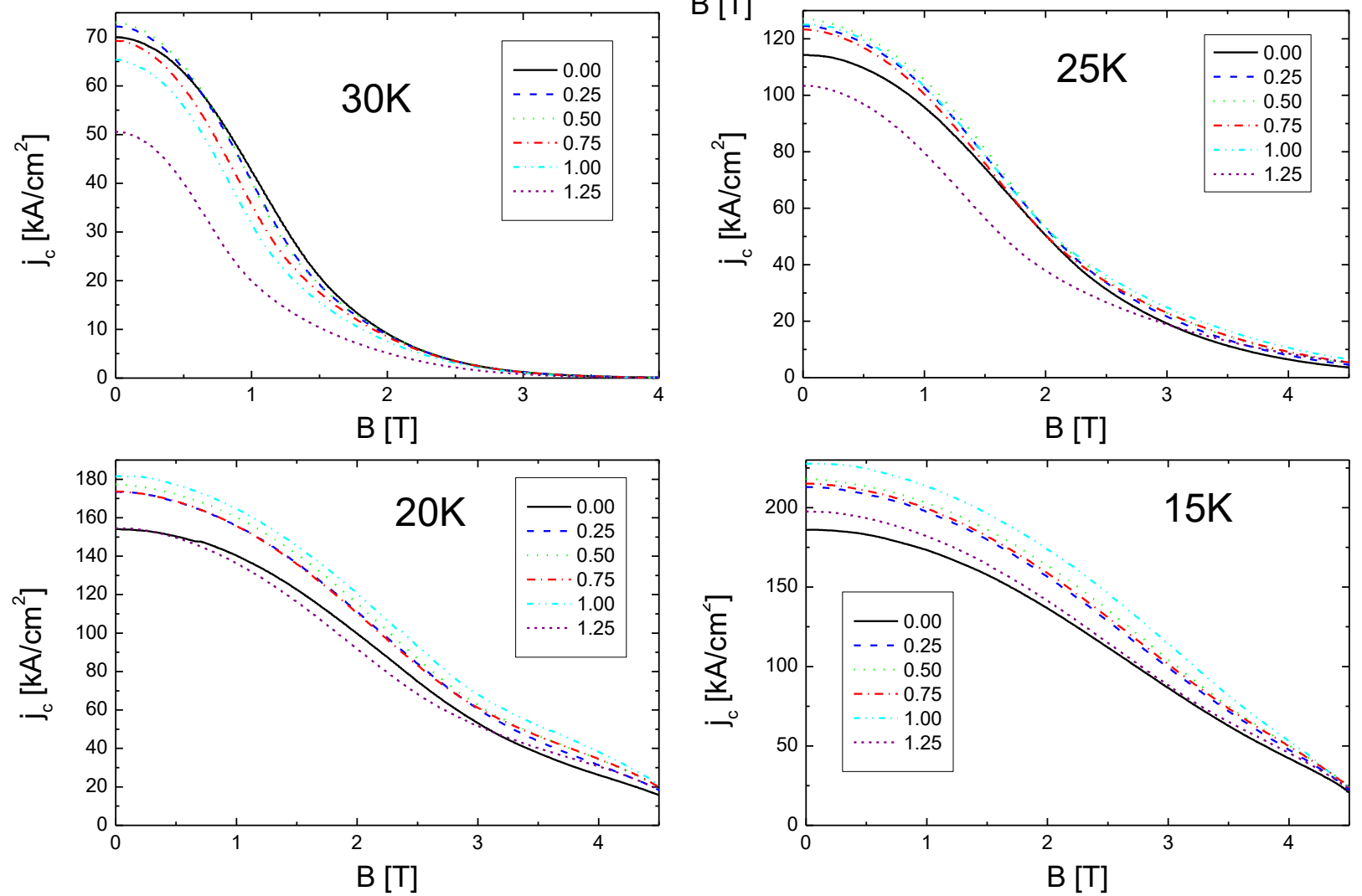

477

Figure 6

479

480

481 

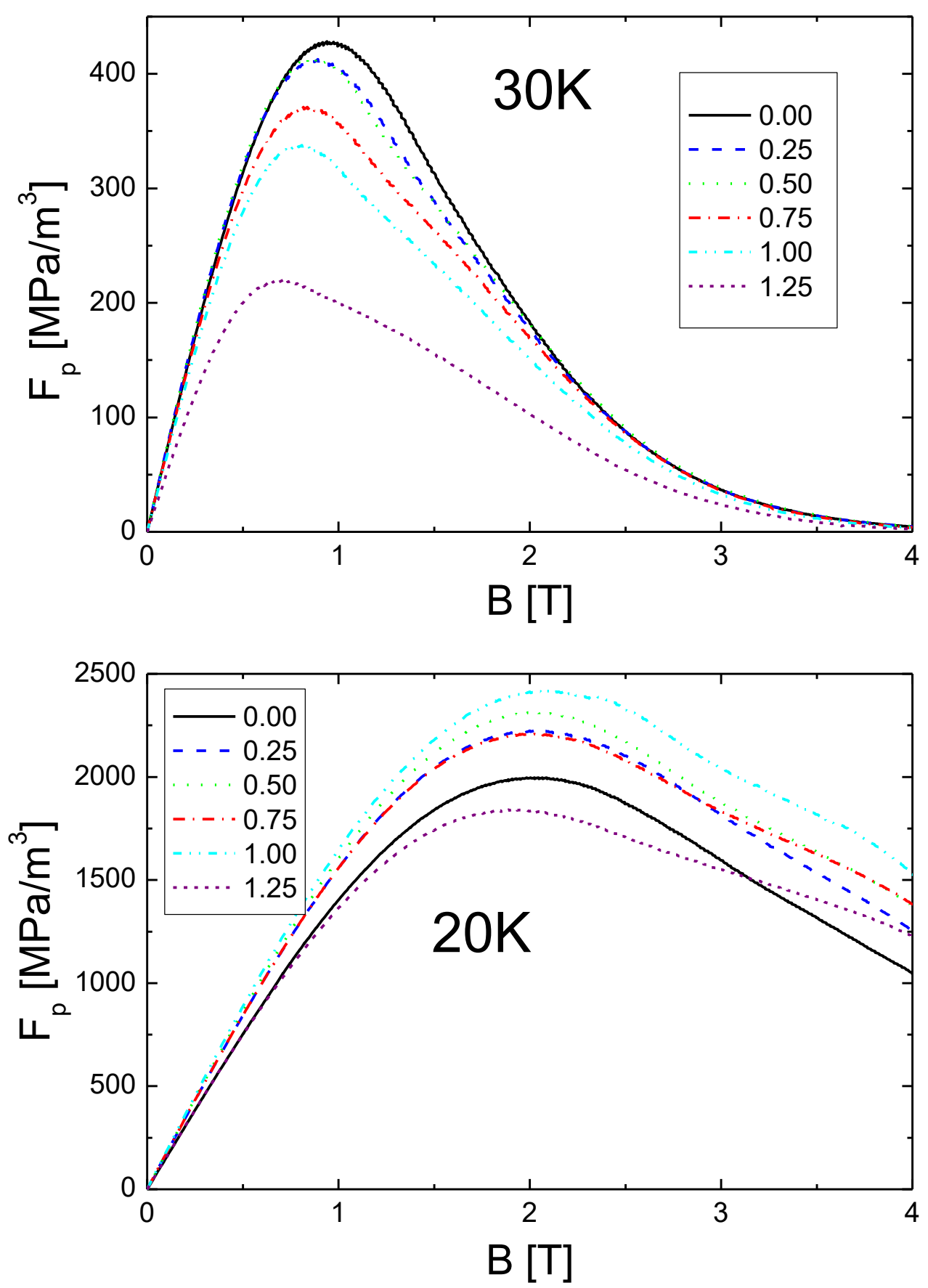

482

483

484

485

486

Figure 7 

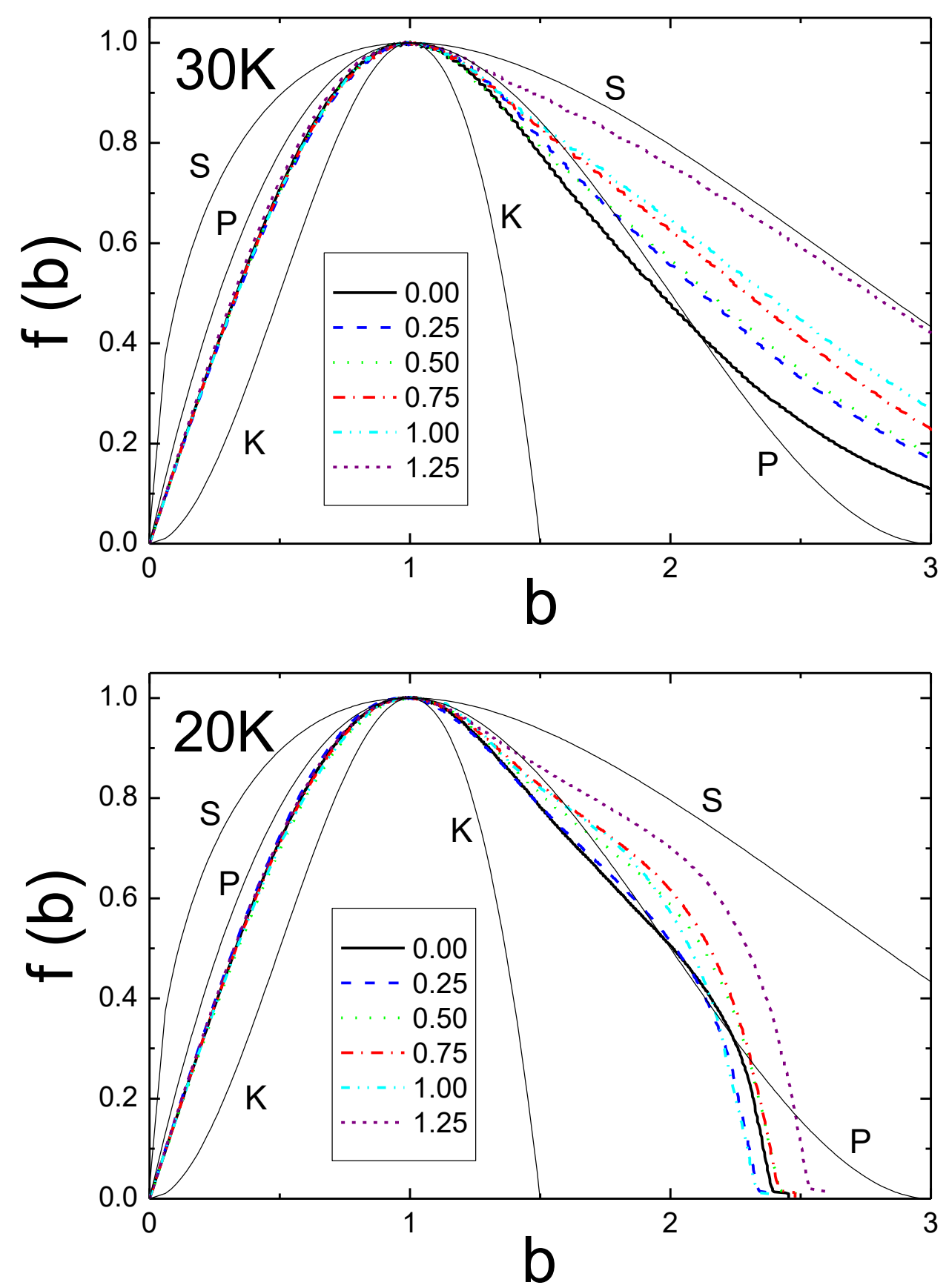

487

488

489

Figure 8

490

491 


\begin{tabular}{|c|c|c|c|c|c|c|c|c|c|c|}
\hline $\begin{array}{l}\text { Methylene Blue } \\
\text { [wt.\%] }\end{array}$ & $\begin{array}{c}\mathrm{a} \\
{[\AA]}\end{array}$ & $\begin{array}{c}\mathrm{c} \\
{[\AA]}\end{array}$ & $\begin{array}{c}\rho \\
{\left[\mathrm{g} / \mathrm{cm}^{3}\right]}\end{array}$ & $\begin{array}{r}\mathrm{T}_{\mathrm{c}} \\
{[\mathrm{K}]}\end{array}$ & $\begin{array}{l}\Delta \mathrm{T}_{\mathrm{c}} \\
{[\mathrm{K}]}\end{array}$ & $\begin{array}{l}\mathrm{FWHM}_{(002)} \\
{\left[^{\circ}\right](2 \theta)}\end{array}$ & $\begin{array}{l}\text { FWHM }_{(110)} \\
{\left[^{\circ}\right](2 \theta)}\end{array}$ & $\begin{array}{l}\mathrm{C}_{\mathrm{XRD}} \\
\quad[\text { Expre }\end{array}$ & $\begin{array}{c}\mathrm{C}_{\mathrm{Tc}} \\
\text { as } \mathrm{x} \text { in } \mathrm{Mg}\end{array}$ & $\mathrm{C}_{\mathrm{nom}}$ \\
\hline 0.00 & $3.0851(3)$ & $3.5223(4)$ & $1.21(2)$ & $38.63(5)$ & $0.60(8)$ & $0.296(5)$ & $0.346(6)$ & 0.000 & 0.000 & 0.000 \\
\hline 0.25 & $3.0839(3)$ & $3.5225(4)$ & $1.32(2)$ & $38.24(5)$ & $0.65(9)$ & $0.308(5)$ & $0.382(8)$ & $0.008(3)$ & $0.005(2)$ & 0.005 \\
\hline 0.50 & $3.0826(2)$ & $3.5229(3)$ & $1.26(2)$ & $38.07(5)$ & $0.58(8)$ & $0.304(5)$ & $0.385(8)$ & $0.010(3)$ & $0.008(3)$ & 0.011 \\
\hline 0.75 & $3.0812(3)$ & $3.5227(4)$ & $1.35(2)$ & $37.66(5)$ & $0.65(9)$ & $0.309(5)$ & $0.388(6)$ & $0.016(3)$ & $0.014(4)$ & 0.016 \\
\hline 1.00 & $3.0798(3)$ & $3.5231(4)$ & $1.29(2)$ & $36.94(5)$ & $0.64(9)$ & $0.308(5)$ & $0.382(8)$ & $0.023(3)$ & $0.024(4)$ & 0.022 \\
\hline 1.25 & $3.0793(3)$ & $3.5229(4)$ & $1.13(2)$ & $36.50(5)$ & $0.76(9)$ & $0.350(6)$ & $0.441(6)$ & $0.026(3)$ & $0.030(4)$ & 0.027 \\
\hline
\end{tabular}

Table 1 


\title{
Supplementary Material
}

\section{Increase of the critical current density of $\mathrm{MgB}_{2}$ superconducting bulk samples by means of methylene blue dye additions}

\author{
J.-C. Grivel1* and K. Rubešová ${ }^{2}$ \\ ${ }^{1}$ Department of Energy Conversion and Storage, Technical University of Denmark, DK-4000 \\ Roskilde, Denmark \\ ${ }^{2}$ University of Chemistry and Technology, Department of Inorganic Chemistry, Technická 5, \\ Prague 6, 166 28, Czech Republic
}

\section{$\mathrm{MgB}_{2}$ grain size}

Figure S1 shows an SEM image (5000 x magnification), where various types of phases are visible. The large, elongated grains consist of $\mathrm{MgB}_{7}$, the grey particles with diameter up to $2 \mu \mathrm{m}$ are made of $\mathrm{MgB}_{4}$, the small white grains are $\mathrm{SiC}$ particles remaining from the grinding pastes and the finally the $\mathrm{MgB}_{2}$ grains form the light grey matrix. The size of the $\mathrm{MgB}_{2}$ grains can be estimated as $1-3 \mu \mathrm{m}$ based on areas, where individual particles are distinguishable. Similar microstructures were observed for all samples.

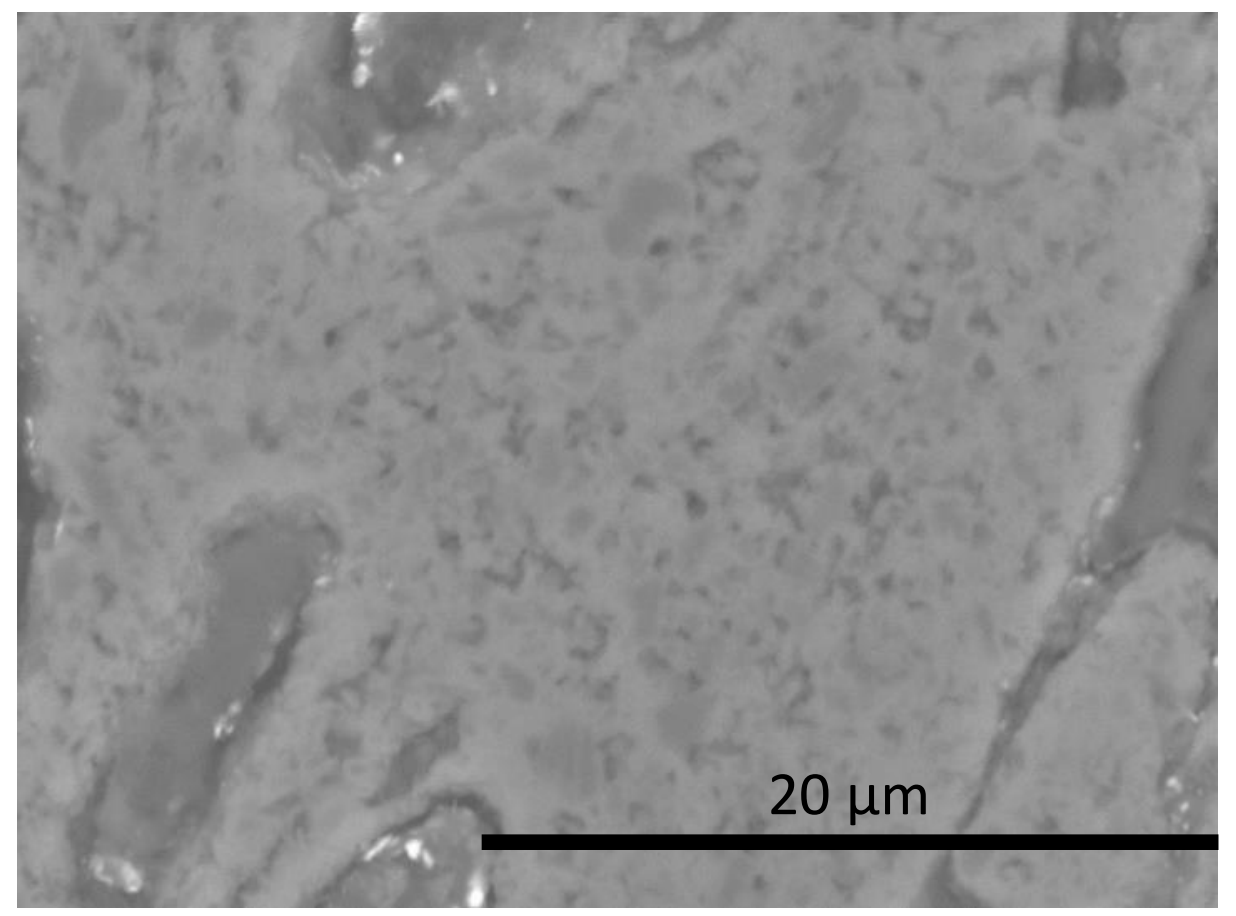

Figure S1: SEM image (backscattering mode) of the undoped sample after reaction. 

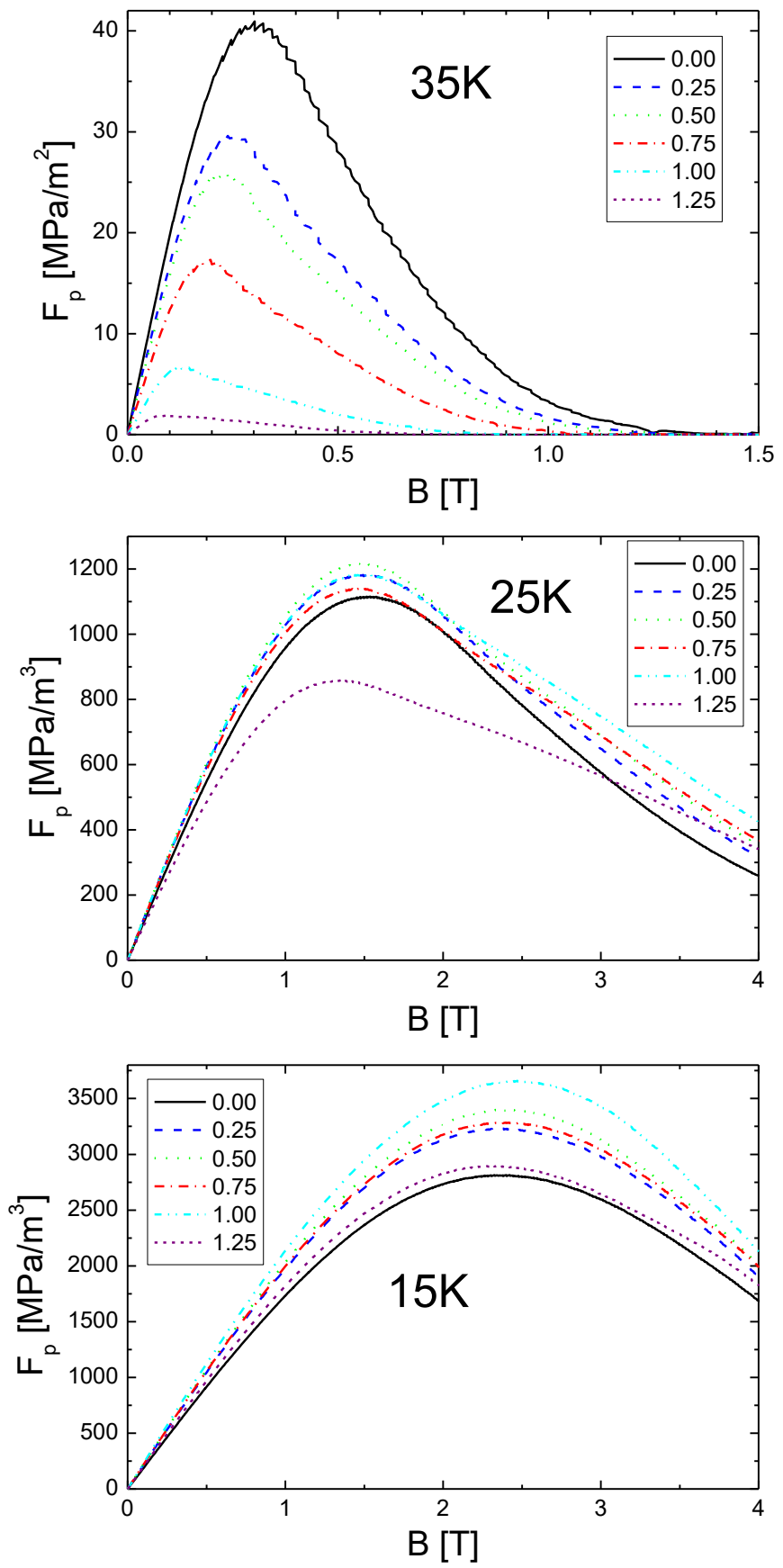

Figure S2: Pinning force $\left(F_{p}\right)$ at $35 \mathrm{~K}, 25 \mathrm{~K}$ and $15 \mathrm{~K}$ versus applied magnetic field (B) for samples with various nominal methylene blue trihydrate contents indicated as wt.\%. 

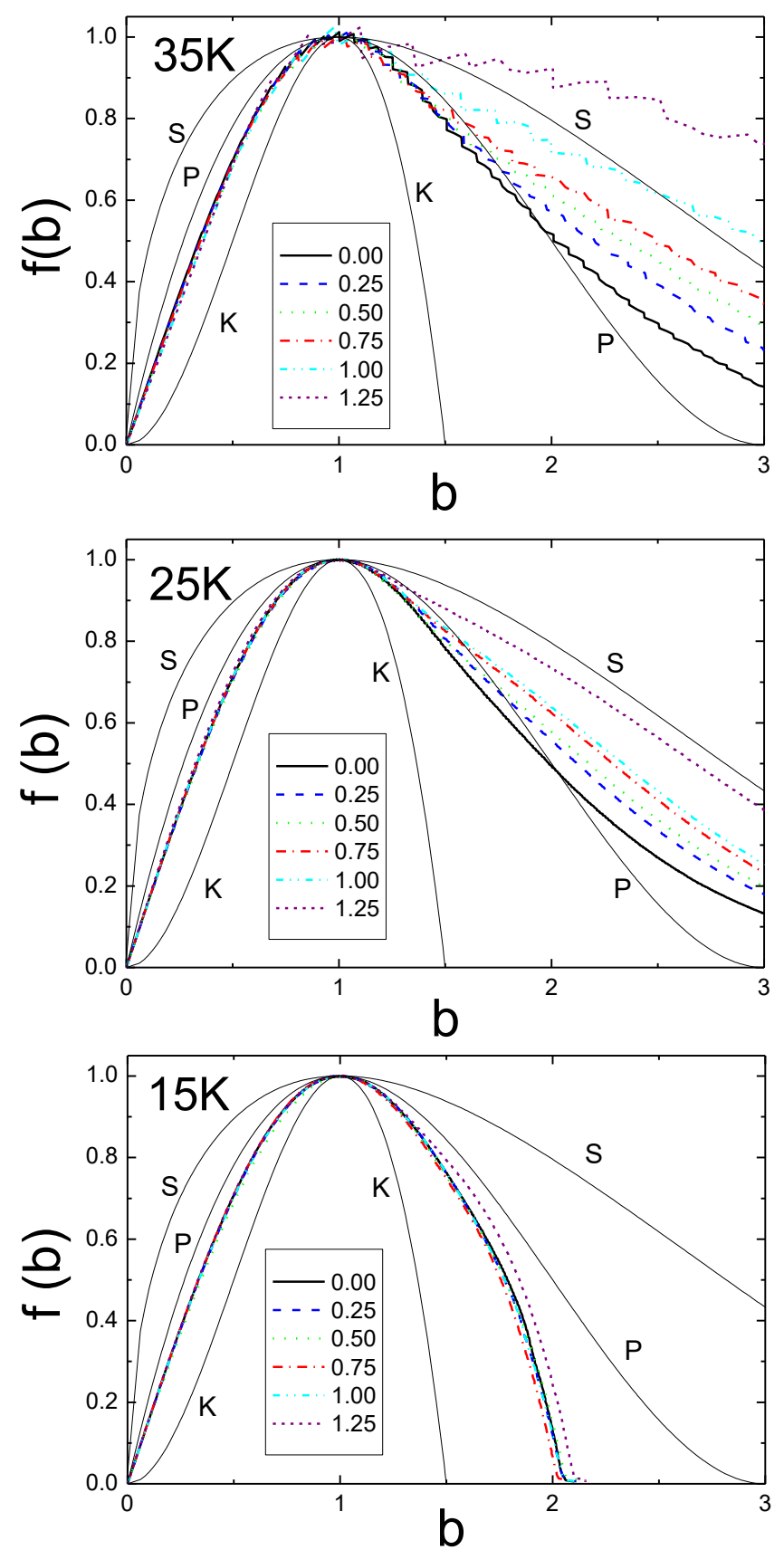

Figure S3: Normalized pinning force $\mathrm{f}(\mathrm{b})=\mathrm{F}_{\mathrm{p}} / \mathrm{F}_{\mathrm{pmax}}$ at $35 \mathrm{~K}, 25 \mathrm{~K}$ and $15 \mathrm{~K}$ versus the normalized magnetic field $\mathrm{b}=\mathrm{B} / \mathrm{B}_{\mathrm{Fpmax}}$. The data for the different nominal methylene blue trihydrate contents indicated as wt.\% are compared to theoretical predictions of three flux pinning mechanism models: surface pinning $(\mathrm{S})$, point pinning $(\mathrm{P})$ and $\Delta \kappa$ pinning $(\mathrm{K})$. 


\begin{tabular}{lccccc}
\hline Doping level (x) & $35 \mathrm{~K}$ & $30 \mathrm{~K}$ & $25 \mathrm{~K}$ & $20 \mathrm{~K}$ & $15 \mathrm{~K}$ \\
\hline 0.00 & 158 & 253 & 289 & 341 & 440 \\
0.25 & 139 & 249 & 281 & 357 & 440 \\
0.50 & 128 & 223 & 273 & 328 & 420 \\
0.75 & 109 & 241 & 271 & 305 & 420 \\
1.00 & 86 & 209 & 260 & 284 & 415 \\
1.25 & 67 & 179 & 177 & 233 & 397 \\
\hline
\end{tabular}

Table S1: $\mathrm{H}_{\mathrm{p}}$ values in $\mathrm{mT}$ for all samples at various temperatures. The uncertainty on all values is of $+/-10 \%$. 